\title{
Competition during the milk-feeding stage influences the development of feeding behavior of pair-housed dairy calves
}

\author{
E. K. Miller-Cushon, ${ }^{*}$ R. Bergeron,† K. E. Leslie,‡ G. J. Mason, $\S$ and T. J. DeVries*1 \\ *Department of Animal and Poultry Science, University of Guelph, Kemptville Campus, 830 Prescott Street, Kemptville, ON, K0G 1J0, Canada \\ †Campus d'Alfred, University of Guelph, Alfred, ON, KOB 1A0, Canada \\ łDepartment of Population Medicine, Ontario Veterinary College, University of Guelph, Guelph, ON, N1G 2W1, Canada \\ §Department of Animal and Poultry Science, University of Guelph, Guelph, ON, N1G 2W1, Canada
}

\begin{abstract}
This study investigated how the feeding behavior of pair-housed calves develops in response to reduced teat and feed place availability. Twenty Holstein bull calves were pair housed and provided with milk replacer (MR) and grain concentrate ad libitum via either (1) 1 teat and feed bucket/pen, such that calves could not feed simultaneously [competitive feeding $(\mathrm{CF})$ ] or (2) 2 teats and feed buckets/pen [noncompetitive feeding $(\mathrm{NCF})]$. The calves were weaned during wk 7 of life by incrementally diluting the MR. Postweaning, all pens were managed identically and offered a complete pelleted diet ad libitum via 2 feed buckets/pen $(\mathrm{NCF})$ in period 1 (wk 8 and 9) and period 3 (wk 12 and 13) and exposed to a competitive challenge with $\mathrm{CF}$ in period 2 (wk 10 and 11). Feeding times and competitive interactions were recorded from video for $3 \mathrm{~d} /$ wk in wk 2,4 , and 6 and $2 \mathrm{~d} / \mathrm{wk}$ in wk 8 to 13 . Meal criteria were used to calculate daily meal frequency, meal time, and synchronized meal time (the percentage of meal time when calves within the pen were engaged in simultaneous meals). Milk replacer intake was subject to a treatment $\times$ week interaction, with calves in $\mathrm{CF}$ pens having lower MR intake (wk 2: 8.3 vs. $10.0 \mathrm{~L} /$ calf per day for $\mathrm{CF}$ vs. $\mathrm{NCF}$ ), but compensating by increasing intake to a greater extent over time (wk 4-5: 13.3 vs. 11.7 $\mathrm{L} / \mathrm{d}$ for $\mathrm{CF}$ vs. $\mathrm{NCF}$ ). Corresponding to MR intake, meal frequencies and feeding times evolved differently over this period, increasing in $\mathrm{CF}$ pens and decreasing in NCF pens (wk 2: 5.8 vs. 11.1 and wk 4-6: 6.2 vs. 5.1 meals/d for CF vs. NCF). Calves in CF pens also spent less time engaged in synchronized meals (28 vs. $51 \%$ of meal time; standard error $=7.1$ ) and displaced each other 5 times more frequently during synchronized eating. Postweaning, calves in previously $\mathrm{CF}$ pens maintained 5 times greater displacement frequencies and had fewer overlapping meals than calves in previ-
\end{abstract}

Received February 18, 2014.

Accepted June 27, 2014.

${ }^{1}$ Corresponding author: tdevries@uoguelph.ca ously NCF pens (34.5 vs. $40.7 \%$ of meals, respectively). Postweaning, when calves were all fed noncompetitively (2 buckets/pen in periods 1 and 3), calves previously fed $\mathrm{CF}$ had greater intakes in period 3 (4.87 vs. 4.44 $\mathrm{kg} / \mathrm{d}$ ) and a tendency for greater intake in period 1 $(2.80$ vs. $2.63 \mathrm{~kg} / \mathrm{d})$, greater rates of intake in period 3 (87.8 vs. $72.0 \mathrm{~g} / \mathrm{min}$ ) and a tendency for greater rates of intake in period 1 (44.3 vs. $38.9 \mathrm{~g} / \mathrm{min}$ ), and greater meal frequencies in both periods (11.1 vs. 9.9 meals/d). In the competitive challenge period ( 1 bucket/pen in period 2), intake, rates of intake, and meal frequencies were subject to treatment $\times$ week interactions: calves in NCF pens had lower intake and meal frequencies, but increased meal frequency, intake, and rate of intake over time to a greater extent than calves previously in $\mathrm{CF}$ pens. These results indicate that calves are able to adapt to moderate competition by increasing meal frequency and that behavioral responses to competition persist postweaning.

Key words: dairy calf, competition, feeding behavior, feed intake

\section{INTRODUCTION}

Evidence exists that social housing improves the growth and welfare of dairy calves, through reducing stress and supporting weight gain around weaning (Chua et al., 2002; De Paula Vieira et al., 2010), encouraging feed intake through socially facilitating feeding behavior (Phillips, 2004; De Paula Vieira et al., 2010), and supporting the development of normal social behavior (Veissier et al., 1994; Duve and Jensen, 2011). However, housing calves in groups poses challenges for feed access, and it is common for group-housed calves to experience competition for access to milk (Jensen, 2004; De Paula Vieira et al., 2010).

In response to competitive pressures while feeding, animals must make trade-offs between daily feed intake, feeding rates, and feeding synchrony (Nielsen, 1999). In heifers and adult cows, reducing available feeding stations or feed bunk space increases intake rates (Harb et al., 1985; Hosseinkhani et al., 2008; DeVries 
and von Keyserlingk, 2009; Proudfoot et al., 2009) and competitive interactions around feed (DeVries et al., 2004; Huzzey et al., 2006; Proudfoot et al., 2009), and decreases meal frequencies (Hosseinkhani et al., 2008; DeVries and von Keyserlingk, 2009). Cows also respond to competition for feed by spending more time feeding at night (Olofsson, 1999), suggesting that feeding synchrony is reduced. This flexibility of feeding behavior suggests that cattle in competitive environments prioritize maintaining intake, achieving this through adapting their feeding patterns and rates of intake. As further evidence, although intake may be negatively affected by competition in certain environments (Proudfoot et al., 2009), it appears to be less consistently affected than feeding rate or meal frequency (Hosseinkhani et al., 2008; DeVries and von Keyserlingk, 2009).

Similar behavioral responses to competition have also been observed in dairy calves, with intake rates and frequencies of competitive displacements at the milk feeder increasing with increasing group size and decreasing teat availability (Jensen, 2004; von Keyserlingk et al., 2004). Results reported by von Keyserlingk et al. (2004) also indicate that a short-term (1-d) reduction in the number of teats available to ad libitumfed group-housed calves negatively affects milk intake. However, these results do not provide insight into how intake and feeding patterns are affected by level of competition over a longer time frame. Thus, it is unclear what mechanisms calves possess to adapt feeding patterns to sustain intake when faced with competition and reduced access to feeders over the course of the milk-feeding stage. Given the increasing prevalence of systems where calves are group housed and provided greater quantities of milk (e.g., computerized feeders for groups of 10 to 15 calves; Weber and Wechsler, 2001; Jensen and Holm, 2003), it is important to ascertain the ability of calves to adapt their feeding behavior and maintain intake when faced with competition at the feeder. Furthermore, little work to date has assessed whether behavior developed in response to levels of competition early in life may persist after weaning off milk. The early environment has been found to affect social behavior later in life; for example, evidence exists that, compared with calves housed individually, calves raised in groups have greater competitive success (Duve et al., 2012) and gain higher places in the herd rank order, as evaluated by competitive displacements later in life (Warnick et al., 1977; Broom and Leaver, 1978).

The overall objective of this study was to assess the effect of competition for feed during the milk-feeding stage, resulting from reduced access to feeding locations, on development of feeding behavior in pairhoused calves. The first hypothesis of this study was that calves would be able to compensate for competition for access to feeding locations for milk and solid feed. Specifically, it was predicted that, over time, calves in competitively fed pens would adapt their milk feeding patterns and social feeding behavior, including feeding synchrony and competitive interactions, to allow similar milk intake and growth compared with calves fed noncompetitively. Additionally, it was predicted that calves provided solid feed competitively would have similar feeding time and intake to calves fed noncompetitively. The second hypothesis of this study was that feeding behavior developed before weaning in response to a competitive feeding environment would persist postweaning and influence the ability of the calf to cope with competitive challenges. It was predicted that, postweaning, calves previously raised in competitively fed pens would have reduced feeding synchrony and be more competitive for access to feed. When subjected to competitive challenge, through restricting access to feed buckets, it was predicted that calves previously raised in competitively fed pens would adjust feeding patterns to maintain intake more effectively than calves raised in a less-competitive environment.

\section{MATERIALS AND METHODS}

\section{Animals and Housing}

Twenty male Holstein calves were used in this study. Calves were purchased and transported to the University of Guelph Kemptville Campus Dairy Education and Research Centre (Kemptville, ON, Canada) where they were managed according to the standard operating procedures of the research facility, in accordance with guidelines set by the Canadian Council on Animal Care (CCAC, 2009) and as approved by the University of Guelph Animal Care Committee (AUP \#1913). All calves received colostrum and arrived at the research facility within $24 \mathrm{~h}$ of birth. Calves were randomly paired with calves of the same age and enrolled immediately in the study; thus, for each pair of calves, the first day of the study corresponded to d 2 of life. The study was conducted from May to August 2012, with all calves enrolled within the first $5 \mathrm{~d}$ of May.

Pairs of calves were housed together in pens (2.4 $\times 1.8 \mathrm{~m}$; width $\times$ depth). Pen walls were solid on 3 sides (1.3 $\mathrm{m}$ in height) with a metal gate at the front. Openings in the gate at the front of the pen provided access to pails for water and feed (pails with 8-L capacity were used preweaning and pails with 20-L capacity were used postweaning). The interior of each pen was bedded with wood shavings, with bedding replaced weekly and fresh bedding added as needed. Calf pens were located under a 3-sided, roofed shelter, with the front of the pen facing the open side of the shelter to 
allow for natural ventilation while protecting the pens from rain. This calf research facility was reserved for the arrival of study calves and was empty before the start of the study.

All calves received injections of $1 \mathrm{~mL}$ of selenium (Dystosel; Pfizer Animal Health, Kirkland, QC, Canada) and $1 \mathrm{~mL}$ of tulathromycin (Draxxin; Pfizer Animal Health) on the day they were placed in the study as a preventive measure to reduce incidence of illness (Stanton et al., 2013). No serious illness was reported throughout the study.

\section{Milk Feeding Procedure}

During the milk-feeding stage, the calves were provided acidified milk replacer ad libitum by teat [according to the procedure outlined by Anderson (2013)]. The feeding setup involved rubber teats (Peach Teats; Skellerup Industries Ltd., Woolston, New Zealand) mounted at the front of the pen and attached to tubes fitted with a one-way valve running into covered buckets placed outside the pen. All buckets, lines, and teats were cleaned daily. Calves were fed Shur-Gain Optivia Advantage Milk Replacer (Nutreco Canada Inc., Guelph, ON, Canada), containing $26 \% \mathrm{CP}$ and $16 \%$ fat. The milk replacer was mixed at a rate of $150 \mathrm{~g} / \mathrm{L}$. The milk replacer was mixed daily in sufficient volume to feed all calves. At the time of preparation, a prediluted form of formic acid [The Acidified Milk Solution (9.8\% formic acid); NOD Apiary Products Ltd., Frankford, ON, Canada] was added to acidify the milk replacer to a target $\mathrm{pH}$ between 4.0 and 4.5 , to prevent microbial growth over the course of the day.

\section{Experimental Design}

Upon enrollment, pens were randomly assigned to 1 of 2 treatments: (1) 1 teat and feed bucket provided per pen, such that calves could not consume milk or feed simultaneously [competitive feeding (CF)] or (2) 2 teats and feed buckets provided per pen [noncompetitive feeding (NCF)]. For CF pens, a single teat was placed in the center at the front of the pen and a single feed bucket was placed to one side of the pen, leaving the adjacent bucket position empty. For NCF pens, 2 teats were placed $50 \mathrm{~cm}$ apart in the center of the pen and 2 feed buckets were placed together on the same side of the pen. Water was available ad libitum in 2 adjacent buckets in all pens.

Fresh milk replacer was provided daily at $0800 \mathrm{~h}$, with the amount replenished at $1600 \mathrm{~h}$ as required to ensure unrestricted intake in all pens. Fresh grain concentrate (Table 1) was delivered daily at $0900 \mathrm{~h}$ in quantities
Table 1. Chemical composition of feeds (mean \pm SD; DM basis)

\begin{tabular}{lcc}
\hline $\begin{array}{l}\text { Chemical } \\
\text { composition }^{1}\end{array}$ & Concentrate $^{2}$ & Pelleted diet $^{3}$ \\
\hline DM (\%) & $87.75 \pm 0.40$ & $91.60 \pm 1.70$ \\
CP (\% of DM) & $18.1 \pm 0.32$ & $21.20 \pm 0.40$ \\
ADF (\% of DM) & $6.51 \pm 0.29$ & $17.40 \pm 0.75$ \\
NDF (\% of DM) & $16.69 \pm 0.30$ & $36.73 \pm 1.01$ \\
NFC (\% of DM) & $54.66 \pm 0.76$ & $30.00 \pm 0.49$ \\
ME (Mcal/kg of DM) & $2.83 \pm 0.030$ & $2.53 \pm 0.040$ \\
Fat (\% of DM) & $4.20 \pm 0.42$ & $4.02 \pm 0.24$
\end{tabular}

${ }^{1}$ Values were obtained from chemical analysis of feed samples. NFC $=100-[\mathrm{CP}(\%)+\mathrm{NDF}(\%)+$ fat $(\%)+\operatorname{ash}(\%)] ; \mathrm{ME}=\mathrm{TDN} \times$ $0.04409 \times 0.82$ [calculated according to NRC (2001) equations].

${ }^{2}$ Supplied by Rooney Feeds Ltd. (Iroquois, ON, Canada). Contained (on an as-is basis) $36.5 \%$ corn, $28 \%$ calf starter supplement supplied by Shur-Gain (Nutreco Canada Inc., Guelph, ON, Canada), 20\% rolled barley, $10 \%$ rolled oats, $2.5 \%$ dilute monensin sodium, $2 \%$ molasses, and $1 \%$ soybean oil.

${ }^{3}$ Shur-Gain High Fiber 20\% Dairy Heifer Ration (Nutreco Canada Inc.).

to ensure ad libitum intake. Calves were weaned from milk replacer during wk 7 by incrementally diluting the milk replacer: $112.5 \mathrm{~g}$ of $\mathrm{DM} / \mathrm{L}$ on $\mathrm{d} 43$ and $44,75 \mathrm{~g}$ of $\mathrm{DM} / \mathrm{L}$ on d 45 and $46,37.5 \mathrm{~g}$ of DM/L on d 47 and 48 , and water offered on d 49 .

Calves were followed for 6 wk postweaning, during which both pens previously fed CF and pens previously fed NCF were managed identically. On the first day of wk 8, all pens were offered a complete pelleted diet (Table 1) ad libitum in place of concentrate. The postweaning stage was split into three 2 -wk periods, with pens managed according to different feeding procedures. In period 1 (wk 8 and 9) and period 3 (wk 12 and 13), feed was provided noncompetitively in all pens in 2 adjacent buckets, such that calves could feed simultaneously. In period 2 (wk 10 and 11), all pens were subjected to a competitive challenge with feed provided in a single bucket, such that calves could not feed simultaneously.

\section{Intake and Growth Measurements}

The intake of solid feed (and milk during the milkfeeding stage) was recorded daily on the pen level based on offered and refused quantities of feed. Calves were weighed at the same time each day on the first $2 \mathrm{~d}$ each week, with repeated measurements made to obtain an accurate weekly weight and account for day-to-day variability.

\section{Feed Sampling and Analysis}

For determination of the DM and nutrient content of the feed and assessment of daily DMI of the calves, 
fresh feed was sampled weekly and individual orts from each calf were sampled twice weekly (on d 1 and 4), just before removal and delivery of fresh feed. This sampling protocol was consistent throughout the study; however, the samples taken changed from concentrate during the milk-feeding stage to the complete pelleted diet in wk 8. All samples were immediately frozen at $-20^{\circ} \mathrm{C}$ until further analysis.

Samples taken for DM and chemical analysis were oven dried at $55^{\circ} \mathrm{C}$ for $48 \mathrm{~h}$ to determine DM content. Fresh samples taken for chemical analysis were ground to pass through a 1-mm screen (Wiley mill; Arthur H. Thomas Co., Philadelphia, PA). These samples were then pooled by 2 -wk time interval ( 3 samples from the milk-feeding stage and 3 from the postweaning stage) and sent to Cumberland Valley Analytical Services Inc. (Maugansville, MD) for analysis of DM $\left(135^{\circ} \mathrm{C}\right.$; AOAC International, 2000; method 930.15$)$, ash $\left(535^{\circ} \mathrm{C}\right.$; AOAC International, 2000; method 942.05), ADF (AOAC International, 2000: method 973.18), NDF with heatstable $\alpha$-amylase and sodium sulfite (Van Soest et al., 1991), and $\mathrm{CP}(\mathrm{N} \times 6.25$; AOAC International, 2000; method 990.03; Leco FP-528 Nitrogen Analyzer; Leco Corp., St. Joseph, MI).

\section{Behavioral Observation}

The behavior of all calves was recorded using 8 color video cameras (Day/Night Camera, model no. WVCP504; Panasonic Corp., Osaka, Japan) fitted with an F0.95/2.8- to 8-mm lens (Fujinon CCTV lens; Fujifilm Corp., Tokyo, Japan). The cameras were connected to a digital video recorder (Digital Disk Recorder, model no. WJ-HD616K; Panasonic Corp.) set to record at 15 images/s and positioned above the pens such that each pen was fully visible from one of the cameras (placed approximately $2 \mathrm{~m}$ in front of the pens and $4 \mathrm{~m}$ from the pen floor). Four red lights $(100 \mathrm{~W})$ were spaced evenly between the cameras, and placed on a timer to provide enough light to record during nighttime hours (on from $1900 \mathrm{~h}$ to $0700 \mathrm{~h}$ ).

During the milk-feeding stage, calves within pens were observed individually for $3 \mathrm{~d}$ at the beginning of wk 2,4 , and 6 . Instantaneous scans were performed at intervals of $30 \mathrm{~s}$ (as validated by Miller-Cushon and DeVries, 2011) to record milk feeding; this behavior was defined as taking place when a calf's mouth was closed on a teat. Competitive behavior occurring when calves were drinking milk was assessed by recording instances of displacements (one calf butts or pushes the other calf away from the teat or feed bucket and replaces them at that feeding station, as defined by von Keyserlingk et al., 2004). In wk 6, the start and end of all occurrences of feeding on concentrate were recorded in addition to milk feeding. Feeding was defined as a calf's head lowered in the feed bucket.

During the postweaning stage, calves within pens were observed individually for $2 \mathrm{~d} / \mathrm{wk}$ (12 observation $\mathrm{d} /$ calf). Instantaneous scans were performed at intervals of $60 \mathrm{~s}$ to record feeding (as validated for postweaning feeding behavior by Miller-Cushon and DeVries, 2011). As during the milk-feeding stage, all instances of displacements were recorded.

\section{Feeding Behavior Analysis}

Meal analysis was performed on feeding data collected for individual calves. For this analysis, meal criteria (the minimum duration of a time interval between meals) were determined for individual calves by week during the milk-feeding stage (with meal criteria determined for both milk-feeding and solid-feed data) and period in the postweaning stage. Using a software package (MIX 3.1.3; MacDonald and Green, 1988), a mixture of normal distributions was fitted to the distributions of logarithmically transformed time intervals between the recorded periods of time spent feeding. A bimodal normal distribution was fitted to the distribution of intervals for each calf in each week. As described by DeVries et al. (2003), the meal criterion was determined from these modeled distributions as the time point at which the distribution curve of intermeal intervals intersects the distribution curve of intrameal intervals.

According to these specific meal criteria, the start and end times of individual meals for each calf on each day were then identified and meal frequencies and durations were determined. Meal synchrony was assessed as the percentage of time calves were both engaged in meals (calculated as the daily duration of time that calves within a pen were engaged in simultaneous meals, as a percentage of total daily meal time) and the percentage of meals that overlapped between calves (calculated as the number of meals, which included simultaneous time, as a percentage of total daily meal frequency). Although calves in $\mathrm{CF}$ pens could not feed simultaneously, it was possible for them to engage in simultaneous meals when their periods of feeding were interspersed with pauses that were shorter in duration than their meal criterion. Synchrony of milk meals was assessed in wk 2, 4, and 6 , and synchrony of both solid feed and milk meals were assessed in wk 6 . Synchrony of solid feed meals was assessed postweaning. Rate of intake was calculated on the pen level as daily intake divided by total feeding time. 


\section{Statistical Analyses}

Data were analyzed separately by stage: milk-feeding stage, weaning, and postweaning. For the milk-feeding stage, intake and growth data (DMI, milk intake, BW, and ADG) were averaged across pen and week. Feeding behavior data obtained from video analysis were averaged by pen across week. To examine the effect of treatment, all data were analyzed using PROC MIXED of SAS (SAS Institute Inc., Cary, NC), treating week as a repeated measure. The model included initial BW as a covariate; the fixed effects of week, treatment, and week $\times$ treatment interaction; and the random effect of pen. The autoregressive model was selected as the variance-covariance matrix structure on the basis of best fit according to the Schwarz Bayesian information criterion. For data subject to significant treatment $x$ week interactions, the Tukey-Kramer adjustment was used in testing for differences between treatments in individual weeks.

Data from the week of weaning (ADG, solid feed intake, and milk intake) were also analyzed using the PROC MIXED of SAS. The model included the fixed effect of treatment and the random effect of pen within treatment.

For the postweaning stage, intake and growth data were averaged across pen and week. Feeding behavior data obtained from video analysis were averaged across calves within pen and across consecutive observation days $(2 \mathrm{~d} / \mathrm{wk})$. All postweaning data were analyzed using a double-repeated-measures model (week and period, where period relates to both the time period and the number of feed buckets provided). Week was modeled with an unstructured variance-covariance structure and period was modeled as autoregressive order 1 . The model included the fixed effects of treatment, week, period, and their interactions, and the random effect of pen within treatment. As it had been hypothesized that response to competition in the postweaning stage may differ between pens previously fed $\mathrm{CF}$ and $\mathrm{NCF}$, in cases of significant 3-way interactions between treatment, week, and period, data were analyzed separately by period to facilitate interpretation. For analysis by period, the model included the fixed effects of treatment, week, and treatment $\times$ week interaction, and the random effect of pen within treatment. Compound symmetry was selected as the variance-covariance matrix structure on the basis of best fit according to the Schwarz Bayesian information criterion.

All data were normally distributed and homogeneity of variance was verified by plotting residuals from the model against predicted values. All values reported are least squares means. Significance was declared at $P \leq$ 0.05 and trends reported at $0.05<P \leq 0.10$.

\section{RESULTS}

The intake of milk replacer was subject to a treatment $\times$ week interaction $(P<0.001$; Figure 1a). Calves in $\mathrm{CF}$ pens had initially lower milk replacer intake (wk 2: 8.3 vs. $10.0 \mathrm{~L} /$ calf; $P=0.03$ ) but increased milk replacer intake between wk 2 and 4 to a greater extent than calves in NCF pens, such that calves in CF pens had greater intake in wk 4 and $5(13.3$ vs. $11.7 \mathrm{~L} / \mathrm{d} ; P$ $<0.03)$. Calves in NCF pens consumed more solid feed over the milk-feeding stage $(P=0.009)$, with intake increasing over time in both treatments (Figure 1b). Growth also differed between treatments, corresponding to differences in milk replacer intake over time, and $\mathrm{ADG}$ and $\mathrm{BW}$ were subject to treatment $\times$ week interactions $(P<0.04$; BW shown in Figure 1c).

In the analysis of milk meals, the average milk meal criterion was $18.3 \pm 1.8 \mathrm{~min}$ and was not affected by treatment or week $(P>0.26)$. Milk feeding times and milk meal frequencies were also subject to treatment $x$ week interactions (Table 2), corresponding to the differences between treatments in milk intake over time: feeding time and meal frequency were initially lower for CF calves $(P<0.02)$ but increased between wk 2 and 4 in $\mathrm{CF}$ pens compared with calves in NCF pens. Milk meal durations, in contrast, were similar between treatments and did not differ over time. Calves in NCF pens spent more time engaged in synchronized milk meals as a percentage of total milk meal time, and a greater percentage of their milk meals involved synchronized feeding (Table 2). Calves in CF pens displaced each other from the teat at a greater rate during synchronized milk meal time and had more frequent displacements per day overall compared with calves in $\mathrm{NCF}$ pens (Table 2).

Solid feed intake behavior during the milk-feeding stage (evaluated during wk 6, the week before weaning) is reported in Table 3 . The solid feed meal criteria for wk 6 averaged $13.0 \pm 0.48$ min and was similar between treatments $(P=0.33)$. Although calves in NCF pens consumed more solid feed overall in the milk-feeding stage, feed intake was similar between treatments when feeding behavior was assessed in wk $6(377 \pm 62.8 \mathrm{~g} / \mathrm{d}$; mean $\pm \mathrm{SE} ; P=0.73)$. However, feeding behavior differed between treatments (Table 3): calves in $\mathrm{CF}$ pens spent less total time consuming concentrate, had greater rates of intake, and tended to have fewer concentrate meals. Meal duration did not differ between treatments. Calves in NCF pens spent more time engaged in synchronized solid feed meals, and a greater percentage of their solid feed meals involved synchronized feeding (Table 3). However, calves in CF pens had a greater degree of synchrony between solid feed meals and milk meals (Table 3). Despite the increased 

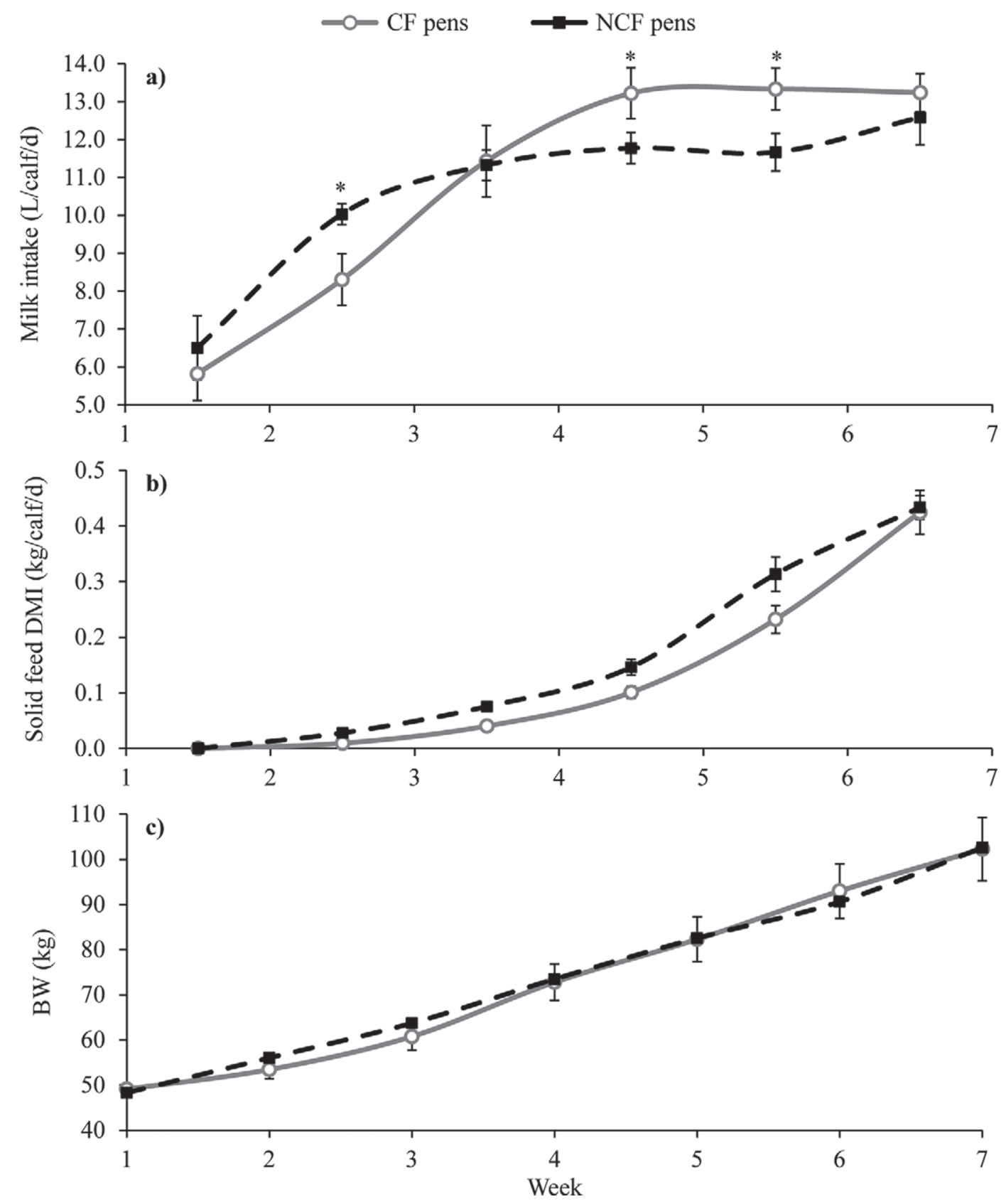

Figure 1. Milk intake (a), solid feed intake (b), and growth (c) of pair-housed calves fed competitively (CF; 1 teat and feed bucket/pen) or noncompetitively (NCF; 2 teats and feed buckets/pen). Values in (a) and (b) are weekly averages. Values in (c) were obtained at the start of each week (averaged across d 1 and 2). All values are averaged across treatment. ${ }^{*}$ Significant difference $(P<0.05)$ between treatments. Error bars represent standard errors of each data point.

synchrony between solid feed meals and milk meals in $\mathrm{CF}$ pens, calves in $\mathrm{NCF}$ pens had greater synchrony overall in wk 6 , when considering synchrony between all milk meals and solid feed meals (59.4 vs. $44.5 \%$ total solid feed and milk meal time; $\mathrm{SE}=4.5 ; P=0.04)$.

During weaning (wk 7), no effect of treatment on solid feed intake $(1.05 \mathrm{~kg} / \mathrm{d} ; \mathrm{SE}=0.08 ; P=0.89)$ or milk replacer intake $(2.02 \mathrm{~kg} / \mathrm{d} ; \mathrm{SE}=0.37 ; P=0.18)$ was detected. Average daily gains were similar between treatments during the week of weaning $(0.17 \mathrm{~kg} / \mathrm{d} ; \mathrm{SE}$ $=0.1 ; P=0.72)$ and $\mathrm{BW}$ was similar at the beginning of wk $8(103.6 \mathrm{~kg} ; \mathrm{SE}=3.87 ; P=0.90)$.

The preweaning feeding treatments affected postweaning intake, growth, and feeding behavior. Overall, during the postweaning stage, intake was subject to a treatment $\times$ period $\times$ week interaction $(P=0.0054)$, indicating that intake evolved differently between treatments in different periods (Figure 2a). Consequently, 


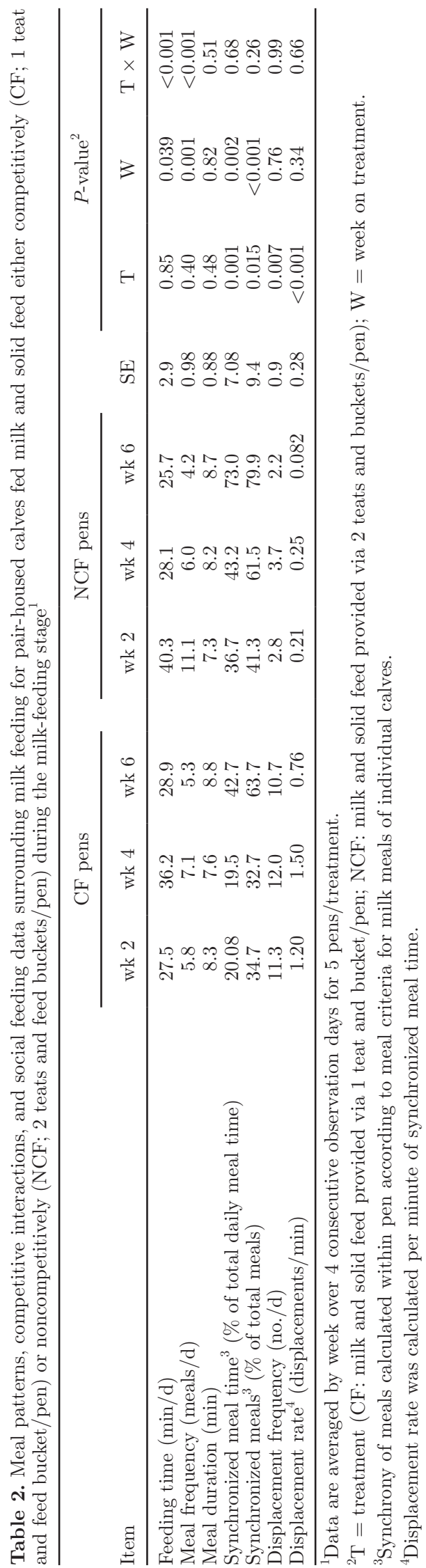

postweaning ADG was subject to a treatment $\times$ period interaction $(P=0.031$; BW shown in Figure $2 \mathrm{~b})$, but final $\mathrm{BW}$ did not differ $(P=0.66)$ between treatments (157.6 vs. $154.7 ; \mathrm{SE}=4.64 ; \mathrm{CF}$ vs. $\mathrm{NCF})$. Although feeding time was similar between treatments over the postweaning stage, rate of intake and meal frequency were subject to treatment $\times$ period $\times$ week interactions (Table 4). The postweaning meal criteria averaged 20.2 $\pm 2.0 \mathrm{~min}$ and were not affected by period or treatment $(P>0.60)$.

Due to the significant treatment $\times$ period $\times$ week interactions, intake, rate of intake, and meal frequency were analyzed separately by period to ease interpretation of data. When calves were all fed noncompetitively with 2 feed buckets provided (period 1 and period 3), calves previously fed CF generally had greater DMI than calves fed NCF (Figure 2a); this was significant in period $3(P=0.04)$ and tended to be different in period $1(P=0.09)$. Calves in previously CF pens also had greater ADG in period 1 (wk 8-9: 1.29 vs. 1.11; SE $=0.07 ; \mathrm{CF}$ vs. $\mathrm{NCF}$ ) and period 3 (wk 12-13: 1.46 vs. 1.17; $\mathrm{SE}=0.09 ; \mathrm{CF}$ vs. $\mathrm{NCF}$ ). Rate of intake and meal frequency also differed between treatments when they were fed noncompetitively: calves in previously $\mathrm{CF}$ pens had consistently greater rates of intake in period 3 $(P=0.04)$ and a tendency for greater rate of intake in period $1(P=0.09)$, as well as more frequent meals in both period $1(P=0.032)$ and $3(P=0.003$; Table 4$)$. Thus, when 2 feed buckets were provided, both before and after the competitive feeding period, calves in previously $\mathrm{CF}$ pens had more frequent meals and generally consumed more feed at a greater rate of intake than calves in previously NCF pens.

During the competitive challenge, when pens were provided with only 1 feed bucket (period 2), intake was subject to a treatment $\times$ week interaction $(P=0.02$; Figure 2a): previously NCF calves initially lagged in intake (wk 10: 5.8 vs. $6.9 \mathrm{~kg} / \mathrm{d} ; P=0.02$ ) but increased their intake between weeks to a greater extent than previously $\mathrm{CF}$ pens, such that intake was similar in wk 11 ( 8.4 vs. $8.5 \mathrm{~kg} / \mathrm{d} ; P=0.9)$. Consequently, ADG of calves in previously NCF pens increased relative to calves in previously $\mathrm{CF}$ pens during this period (wk 10-11: 1.29 vs. $1.21 ; \mathrm{SE}=0.06$; $\mathrm{NCF}$ vs. $\mathrm{CF}$; $\mathrm{BW}$ shown in Figure $2 \mathrm{~b}$ ). Rates of intake in period 2 were also subject to a treatment $\times$ week interaction $(P=$ 0.04 ), with calves in previously NCF pens tending to consume their feed more slowly in wk 10 (53.9 vs. 69.7 $\mathrm{g} / \mathrm{d} ; P=0.07)$ and increasing their rates of intake to a greater extent between weeks, such that rates of intake were similar between treatments in wk 11 (78.2 vs. $80.4 ; P=0.9 ; \mathrm{NCF}$ vs. $\mathrm{CF}$ ). Meal frequencies were similarly subject to a treatment $\times$ week interaction in period $2(P=0.0041)$ : calves in previously $\mathrm{NCF}$ 
Table 3. Solid feed intake behavior of pair-housed calves fed milk and solid feed either competitively (CF; 1 teat and feed bucket/pen) or noncompetitively (NCF; 2 teats and feed buckets/pen) in wk 6 of the milk-feeding stage $^{1}$

\begin{tabular}{|c|c|c|c|c|}
\hline \multirow[b]{2}{*}{ Item } & \multicolumn{2}{|c|}{ Treatment $^{2}$} & \multirow[b]{2}{*}{ SE } & \multirow[b]{2}{*}{$P$-value } \\
\hline & $\mathrm{CF}$ & $\mathrm{NCF}$ & & \\
\hline Feeding time $(\min / \mathrm{d})$ & 4.85 & 7.70 & 0.73 & 0.019 \\
\hline Meal frequency (meals/d) & 6.75 & 8.35 & 0.55 & 0.09 \\
\hline Meal duration ( $\mathrm{min} / \mathrm{meal})$ & 1.97 & 2.4 & 0.34 & 0.41 \\
\hline Rate of intake $(\mathrm{g} / \mathrm{min})$ & 40.2 & 23.5 & 4.7 & 0.016 \\
\hline Synchronized meal time ${ }^{3}(\%$ of total daily meal time) & 3.49 & 19.16 & 3.4 & 0.01 \\
\hline Synchronized meals ${ }^{3}$ ( $\%$ of total meals) & 6.35 & 19.37 & 1.5 & $<0.001$ \\
\hline Synchrony with milk meals ${ }^{4}$ ( $\%$ of solid feed meal time) & 46.0 & 4.42 & 9.9 & 0.018 \\
\hline \multicolumn{5}{|c|}{${ }^{1}$ Data are averaged over $4 \mathrm{~d}$ of observation in wk 6 for 5 pens/treatment. } \\
\hline \multicolumn{5}{|c|}{$\begin{array}{l}{ }^{2} \mathrm{CF} \text { : milk and solid feed provided via } 1 \text { teat and bucket/pen; NCF: milk and solid feed provided via } 2 \text { teats } \\
\text { and buckets/pen. } \\
{ }^{3} \text { Synchrony of solid feed meals calculated within pen according to meal criteria for solid feed meals of individual } \\
\text { calves. }\end{array}$} \\
\hline
\end{tabular}

pens had initially fewer meals (wk 10: 9.6 vs. $11.5 ; P=$ $0.006 ; \mathrm{NCF}$ vs. CF) but increased meal frequency to a greater extent between weeks such that meal frequency was similar between treatments in wk 11 (10.9 vs. 11.0 meals $/ \mathrm{d} ; P=0.9$ ). Thus, when initially exposed to a competitive feeding environment, calves in previously NCF pens consumed less feed, ate more slowly, and had fewer meals than calves in previously $\mathrm{CF}$ pens. However, calves in previously NCF pens quickly increased rate of intake and meal frequency, such that intake and behavior were similar between treatments at the end of the competitive feeding period (period 2).

Overall during the postweaning stage, calves previously fed NCF also had longer meals and a greater percentage of their meals included synchronized meal time (Table 4). The percentage of synchronized meal time decreased across treatments during the competitive feeding period (period 2) but with no treatment effect. Calves in previously CF pens consistently displaced each other more frequently, and the frequency of displacements increased across treatments when all calves were fed competitively in period 2 (Table 4). The rate of displacement at the feed bucket during synchronized meal time was subject to a treatment $x$ period interaction, with calves in previously $\mathrm{CF}$ pens increasing their rate of displacement in period 2 to a greater extent than those in previously NCF pens.

\section{DISCUSSION}

It is common for group-housed dairy calves to experience competition for access to milk, such as displacements and contacts at the feeder (Jensen 2004; von Key- serlingk et al., 2004). Consistent with our hypothesis, the results of this study suggest that, over time, calves are able to adapt to reduced teat access and achieve similar intake. This adaptation is evident in the effect of treatment on evolution of milk intake and milk meal frequency between weeks, with calves fed competitively initially lagging in milk meal frequency and milk intake but increasing meal frequency and, consequently, milk intake, to a greater extent over time. Further, although growth over time was different between treatments, corresponding to milk intake, BW and intake were similar at weaning, indicating that calves fed competitively had successfully compensated for an early lag in intake and growth. Researchers have previously noted shortterm effects of competition on milk meal frequency and milk intake of calves, with meal frequency and milk intake decreasing when the number of teats available to group-housed calves is reduced for $1 \mathrm{~d}$ (von Keyserlingk et al., 2004) and when calves are first exposed to group housing with a single milk feeder at mixing with older animals (O'Driscoll et al., 2006). Compared with these previous short-term studies, the present results suggest that, when followed for longer periods of time, moderate competition does not have a consistent effect on milk meal frequency and milk intake, as calves adapt feeding patterns in response to greater competition to achieve similar intake.

Adaptation of milk feeding patterns in response to competition involved changes in meal frequency rather than meal duration: whereas meal frequency was subject to a treatment $\times$ week interaction, mirroring changes in milk intake, meal duration was consistent over time. Thus, calves in $\mathrm{CF}$ pens began having more frequent meals to increase milk intake, but did not adapt milk 

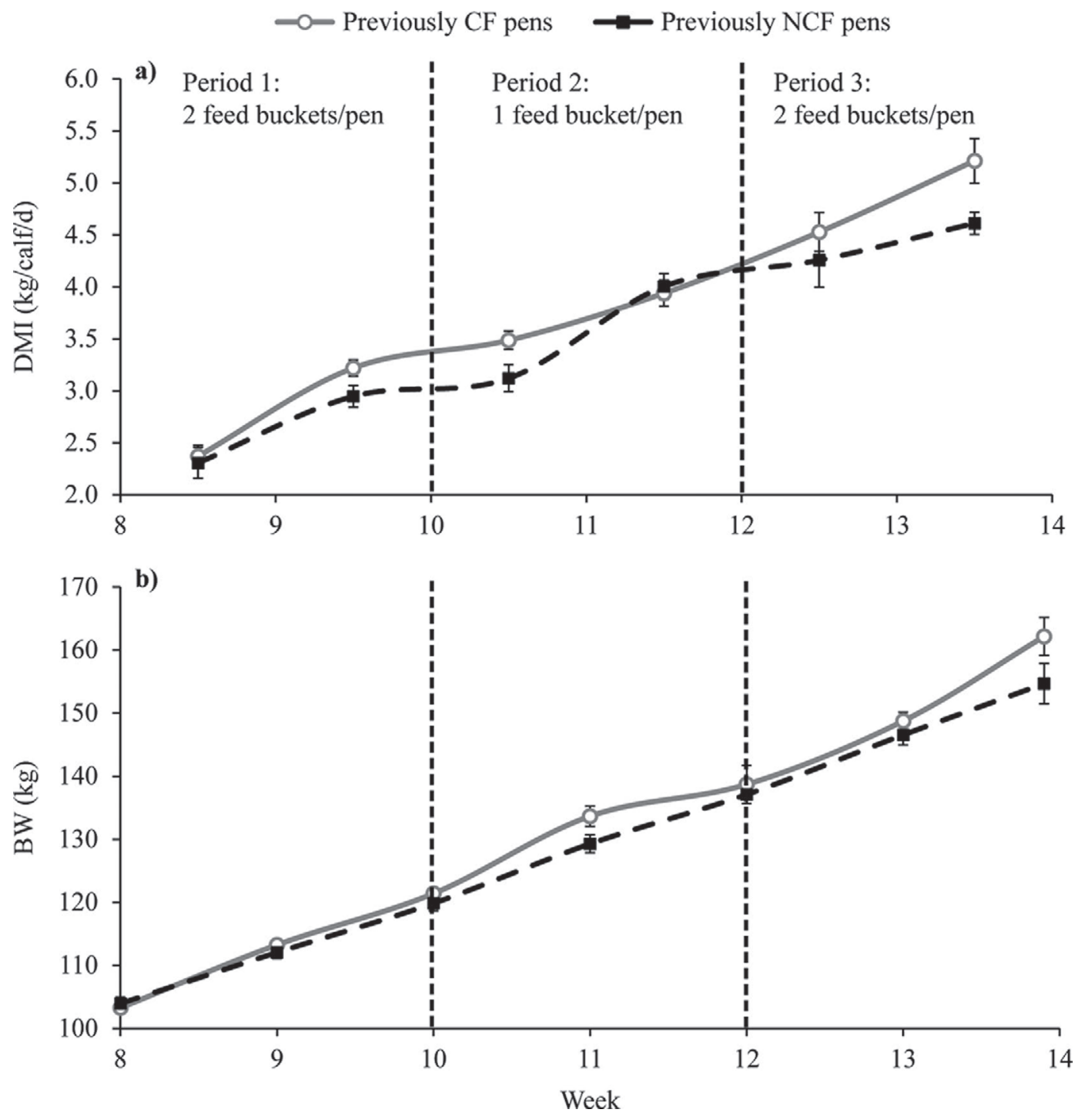

Figure 2. Postweaning DMI (a) and growth (b) of pair-housed calves fed competitively (CF; 1 teat and feed bucket/pen) or noncompetitively (NCF; 2 teats and feed buckets/pen) during the milk-feeding stage. After weaning, all pens were offered solid feed via 2 buckets in period 1 (wk 8 and 9) and period 3 (wk 12 and 13) and 1 bucket in period 2 (wk 10 and 11). Values in (a) are weekly averages. Values in (b) were obtained at the start of each week (averaged across d 1 and 2). All values are averaged across treatment. Error bars represent standard errors of each data point.

meal size or duration. In comparison, Collier and Johnson (1990) describe how animals typically respond to an increasing cost of access to feed, such as an increase in competition, with reduced meal frequency and increased meal size to sustain intake. Whereas milk meal duration was not influenced by competition for milk in the present study, O'Driscoll et al. (2006) reported that, upon mixing with older animals, calves were able to partially compensate for reduced frequency of visits to a milk feeder by increasing visit duration and meal size. Similarly, increased competition for access to feeders results in fewer meals of longer duration in growing heifers (DeVries and von Keyserlingk, 2009) and adult cows (Hosseinkhani et al., 2008). It is unclear why calves in competitively fed pens in the present study did not increase meal duration to maintain intake when meal frequency was reduced early in the milk-feeding stage. Similar to the present results, von Keyserlingk et al. (2004) reported that calves did not compensate for fewer meals by increasing meal duration. Those authors also reported that reduced teat availability resulted in an increase in the number of displacements at the teat, as noted in the present study. It is possible, then, that calves are less likely to increase meal duration when they are frequently displaced during a meal. In support of this, O'Driscoll et al. (2006) noted that calves rarely displaced each other when provided milk via a feeder that offered some protection to the feeding calf, possi- 
bly explaining why calves in that study increased meal duration to compensate for reduced meal frequency. Thus, feeding systems that discourage displacements (e.g., provision of barriers; Jensen et al., 2008) may also support the ability of calves to increase meal duration and compensate for reduced meal frequency when a limited number of feeders are available.

Whereas milk meal frequency and, consequently, milk intake evolved differently over time between treatments, social feeding behavior and frequency of displacements at the teat were not subject to corresponding treatment $\times$ week interactions. This suggests that changes in milk meal frequency were not facilitated by changes in meal synchrony or competitive behavior surrounding milk feeding. It has been speculated that calves may adapt to a social hierarchy by attempting to minimize competitive interactions with other calves (O'Driscoll et al., 2006). In line with this thinking, it was predicted in the present study that calves in pens with reduced teat access would spend increasingly less time engaged in synchronized milk meals as they adapted to the competitive environment, such that they could feed more efficiently and avoid competitive interactions at the feeding area. In contrast, although restricting teat access resulted in less milk meal synchrony and more frequent displacements at the teat, the percentage of time engaged in synchronized milk meals increased over time across treatments. Further, calves with restricted teat access had greater synchrony between solid feed meals and milk meals, indicating that they were engaging in social feeding while at different feeding stations. Synchronization of feeding and other behaviors is common in grazing ruminants (Miller and Wood-Gush, 1991; Rook and Huckle, 1995); further, an increase over time in synchrony of feeding has also been noted in groups of 4 calves raised with a foster cow (Loberg, 2007). The increase in synchronized feeding despite competition in the environment may be attributed to social facilitation, with the strength of social cues greater than motivation to avoid competitive interactions. It is also possible that calves actually prefer to feed socially, as has been demonstrated in pigs (Nielsen et al., 1996). These results indicate that synchronized feeding time is relatively inflexible, either due to strength of external cues or preference for social feeding, and that providing multiple feeding positions to allow for synchronized feeding may encourage intake in group-housed calves.

Solid feed intake was also affected by treatment, with calves fed noncompetitively via 2 feed buckets consuming more solid feed over the course of the milk-feeding stage. This difference in solid feed intake may be partly due to differences in milk intake over time (see Figure $1 \mathrm{a}$ and $\mathrm{b}$ ), rather than a direct result of providing a second feed bucket: whereas CF calves compensated for 
an early lag in milk intake by consuming more milk in later weeks, milk intake of calves in NCF pens plateaued slightly in later weeks, although concentrate intake increased. It is also possible that providing means for calves to feed simultaneously enhanced solid feed intake through enabling greater social facilitation of feeding behavior, which is commonly observed in group-housed calves (Phillips, 2004; De Paula Vieira et al., 2010). Although, anecdotally, no incidences of displacement for access to solid feed were observed, analysis of solid feed intake behavior in wk 6 did indicate that $\mathrm{CF}$ calves had greater rates of solid feed intake, suggesting that they may have experienced competitive pressure from their pen-mate (Nielsen, 1999), which possibly reduced time spent at the feed bucket.

As hypothesized, calves fed competitively before weaning maintained increased competitive behavior postweaning. Consequently, calves raised in $\mathrm{CF}$ pens had greater rates of intake, which is a common response to increasing competition in the environment (Nielsen, 1999; DeVries and von Keyserlingk, 2009). Evidence also exists in weaned heifers that competitive behavior may persist once learned: Greter et al. (2010) reported that the method of feed delivery affected the frequency of displacements at the bunk, and that heifers previously provided concentrate separately from forage continued to displace each other more frequently, even once all pens were provided the same mixed ration. Despite greater rate of intake in previously competitively fed calves, feeding time was similar between treatments, such that intake was greater in previously competitively fed calves during the postweaning periods when feed access was not restricted. This was surprising, as feeding patterns usually adapt to maintain consistent intake in a changing environment (Collier and Johnson, 1990) and intake levels are often resilient to increasing competition (Hosseinkhani et al., 2008; DeVries and von Keyserlingk, 2009). It is possible that calves raised in $\mathrm{CF}$ pens would have regulated their intake to match calves in previously NCF pens over a longer period of time.

Preweaning environment affected response to the competitive challenge period, with calves in previously NCF pens initially having fewer meals, consuming less feed, and eating more slowly when first presented with a CF environment. However, calves in previously NCF pens increased their meal frequencies and intake to a greater extent between weeks than calves in previously $\mathrm{CF}$ pens, mirroring the preweaning response of calves to reduced teat access. These results suggest that intake and feeding patterns of calves raised in $\mathrm{CF}$ pens were less affected by changing levels of competition, whereas calves raised in NCF pens were more affected when initially facing competition for access to feed, but rapidly adapted their feeding patterns when faced with competition. Similar to the present results, evidence exists that calves with previous social contact are able to access feed more successfully during a competitive test than calves raised individually (Duve et al., 2012). Social contact before weaning has also been found to affect dominance hierarchy later in life (Warnick et al., 1977; Broom and Leaver, 1978), suggesting that early experience influences development of social behavior. The present results suggest that exposure to competition in the preweaning period is influential in development of social behavior or feeding patterns which allow calves to cope with a competitive challenge. It is interesting to note that, despite exposing calves raised in NCF pens to competition in period 2, the differences in feeding patterns between treatments observed in period 1 reemerged in period 3 (as discussed above). Although it is possible that prolonged exposure to competition postweaning could override effects of the preweaning environment, the persistence of differences in competitive behavior after 6 wk of similar management suggests that experiences before weaning are critical for development of social behavior, as is apparent in social housing for calves (Warnick et al., 1977; Broom and Leaver, 1978).

Although the present results indicate that calves adapted to competition for access to milk, it is unclear whether these results can be generalized to environments with a greater degree of competition. It is becoming increasingly common for calves to be housed on commercial farms in larger groups (e.g., commonly at least 10 to 15 calves with access to a single feeder; Weber and Wechsler, 2001; Jensen and Holm, 2003), such that teat access may be more restricted and a greater range of calf age and size within larger pens may prompt more competition at the feeder (Hepola, 2003). Given the extent to which the relatively moderate competition in the present study imposed restrictions on milk intake and growth over time (i.e., treatment $\times$ week interactions; Figure 1a and 1c), it is possible that some calves may not be able to compensate for reduced teat access and achieve optimal milk intake in larger, more competitive groups. Restrictions placed by teat availability on intake and growth may be especially critical early in life, as recent evidence suggests that milk intake of ad libitum-fed calves in only the first 4 $\mathrm{d}$ of life is positively correlated with weight gain and health until weaning (Rabeyrin et al., 2013). Thus, we encourage further research to assess the ability of calves in larger groups to adapt their feeding patterns and maintain milk intake, particularly early in life, in response to increasing competitive pressure at the feeder. 


\section{CONCLUSIONS}

Although reduced teat access negatively affected milk intake and meal frequency early in the milk-feed stage, calves compensated by increasing meal frequency and milk intake to a greater extent over time, such that $\mathrm{BW}$ were similar at weaning. Behavioral responses developed in response to competition in the milkfeeding stage persisted postweaning. When calves were provided enough feed buckets to feed simultaneously, calves raised in $\mathrm{CF}$ pens displaced each other more frequently and consumed more feed at a greater rate of intake. During a competitive challenge period when pairs of calves were provided a single feed bucket, such that they could not feed simultaneously, calves raised in $\mathrm{CF}$ pens maintained relatively consistent feeding patterns, whereas calves raised in NCF pens initially had fewer meals and consumed less feed but increased meal frequency, rate of intake, and intake between weeks to a greater extent. Overall, these results suggest that calves are able to adapt feeding patterns to compensate for competition before weaning. Further, these results suggest that competitive behavior and feeding patterns acquired early in life can persist after weaning and affect how calves respond to competitive challenges.

\section{ACKNOWLEDGMENTS}

We thank the staff and students at the University of Guelph, Kemptville Campus Dairy Education and Research Centre (Kemptville, ON, Canada). In particular, we thank Megan Bruce, Morgan Overvest, and John Wynands of the University of Guelph, Kemptville Campus for their technical assistance. E. K. Miller-Cushon was supported by a Natural Sciences and Engineering Research Council of Canada (NSERC, Ottawa, ON, Canada) Canada Graduate Scholarship. This project was funded through a NSERC Discovery Grant ( $\mathrm{T}$. J. DeVries); an Ontario Ministry of Agriculture, Food and Rural Affairs (OMAFRA, Guelph, ON, Canada)/ University of Guelph Production Systems research grant; and support from Nutreco Canada Inc. (Guelph, ON, Canada). This project was also supported through contributions from the Canadian Foundation for Innovation (CFI, Ottawa, ON, Canada) and the Ontario Research Fund.

\section{REFERENCES}

Anderson, N. G. 2013. Group housing and feeding of milk-fed calves: Moving closer to nature's way. Ontario Ministry of Agriculture, Food, and Rural Affairs. Accessed Feb. 1, 2014. http://www.omafra.gov.on.ca/english/livestock/dairy/facts/grouphousing.htm.

AOAC International. 2000. Official Methods of Analysis. Vol. I. 17th ed. AOAC International, Arlington, VA.
Broom, D. M., and J. D. Leaver. 1978. Effects of group-rearing or partial isolation on later social behaviour of calves. Anim. Behav. 26:1255-1263.

CCAC (Canadian Council on Animal Care). 2009. CCAC Guidelines on the Care and Use of Farm Animals in Research, Teaching and Testing. Canadian Council on Animal Care, Ottawa, ON, Canada.

Chua, B., E. Coenen, J. van Delen, and D. M. Weary. 2002. Effects of pair versus individual housing on the behavior and performance of dairy calves. J. Dairy Sci. 85:360-364.

Collier, G., and D. F. Johnson. 1990. The time window of feeding. Physiol. Behav. 48:771-777.

De Paula Vieira, A., M. A. G. von Keyserlingk, and D. M. Weary. 2010. Effects of pair versus single housing on performance and behavior of dairy calves before and after weaning from milk. J. Dairy Sci. 93:3079-3085.

DeVries, T. J., and M. A. G. von Keyserlingk. 2009. Competition for feed affects the feeding behavior of growing dairy heifers. J. Dairy Sci. 92:3922-3929.

DeVries, T. J., M. A. G. von Keyserlingk, and D. M. Weary. 2004. Effect of feeding space on the inter-cow distance, aggression, and feeding behavior of free-stall housed lactating dairy cows. J. Dairy Sci. 87:1432-1438.

DeVries, T. J., M. A. G. von Keyserlingk, D. M. Weary, and K. A. Beauchemin. 2003. Measuring the feeding behavior of lactating dairy cows in early to peak lactation. J. Dairy Sci. 86:3354-3361.

Duve, L. R., and M. B. Jensen. 2011. The level of social contact affects social behaviour in pre-weaned dairy calves. Appl. Anim. Behav. Sci. 135:34-43.

Duve, L. R., D. M. Weary, U. Halekoh, and M. B. Jensen. 2012. The effects of social contact and milk allowance on responses to handling, play, and social behavior in young dairy calves. J. Dairy Sci. 95:6571-6581.

Greter, A. M., K. E. Leslie, G. J. Mason, B. W. McBride, and T. J. DeVries. 2010. Feed delivery method affects the learning of feeding and competitive behavior in dairy heifers. J. Dairy Sci. 93:37303737.

Harb, M. Y., V. S. Reynolds, and R. C. Campling. 1985. Eating behaviour, social dominance and voluntary intake of silage in group-fed milking cattle. Grass Forage Sci. 40:113-118.

Hepola, H. 2003. Milk feeding systems for dairy calves in groups: Effects on feed intake, growth and health. Appl. Anim. Behav. Sci. $80: 233-243$.

Hosseinkhani, A., T. J. Devries, K. L. Proudfoot, R. Valizadeh, D. M. Veira, and M. A. G. von Keyserlingk. 2008. The effects of feed bunk competition on the feed sorting behavior of close-up dry cows. J. Dairy Sci. 91:1115-1121.

Huzzey, J. M., T. J. DeVries, P. Valois, and M. A. G. von Keyserlingk. 2006. Stocking density and feed barrier design affect the feeding and social behavior of dairy cattle. J. Dairy Sci. 89:126-133.

Jensen, M. B. 2004. Computer-controlled milk feeding of dairy calves: The effects of number of calves per feeder and number of milk portions on use of feeder and social behavior. J. Dairy Sci. 87:34283438 .

Jensen, M. B., A. M. de Passillé, M. A. G. von Keyserlingk, and J. Rushen. 2008. A barrier can reduce competition over teats in pairhoused milk-fed calves. J. Dairy Sci. 91:1607-1613.

Jensen, M. B., and L. Holm. 2003. The effect of milk flow rate and milk allowance on feeding related behaviour in dairy calves fed by computer controlled milk feeders. Appl. Anim. Behav. Sci. $82: 87-100$.

Loberg, J. M. 2007. Behaviour of foster cows and calves in dairy production: Acceptance of calves, cow-calf interactions and weaning. $\mathrm{PhD}$ Thesis. Department of Animal Environment and Health, Swedish University of Agricultural Sciences, Skara, Sweden.

MacDonald, P. D. M., and P. E. J. Green. 1988. User's Guide to Program MIX: An Interactive Program for Fitting Mixtures of Distributions. Release 2.3, January 1988. Ichthus Data Systems, Hamilton, ON, Canada.

Miller, K., and D. G. M. Wood-Gush. 1991. Some effects of housing on the social behaviour of dairy cows. Anim. Prod. 53:271-278. 
Miller-Cushon, E. K., and T. J. DeVries. 2011. Technical note: Validation of methodology for characterization of feeding behavior of dairy calves. J. Dairy Sci. 94:6103-6110.

Nielsen, B. L. 1999. On the interpretation of feeding behaviour measures and the use of feeding rate as an indicator of social constraint. Appl. Anim. Behav. Sci. 63:79-91.

Nielsen, B. L., A. B. Lawrence, and C. T. Whittemore. 1996. Feeding behaviour of growing pigs using single or multi-space feeders. Appl. Anim. Behav. Sci. 47:235-246.

NRC. 2001. Nutrient Requirements for Dairy Cattle. 7th rev. ed. Natl. Acad. Sci., Washington, DC.

O'Driscoll, K., M. A. G. von Keyserlingk, and D. M. Weary. 2006. Effects of mixing on drinking and competitive behavior of dairy calves. J. Dairy Sci. 89:229-233.

Olofsson, J. 1999. Competition for total mixed diets fed for ad libitum intake using one or four cows per feeding station. J. Dairy Sci. 82:69-79.

Phillips, C. J. C. 2004. The effects of forage provision and group size on the behavior of calves. J. Dairy Sci. 87:1380-1388.

Proudfoot, K. L.. D. M. Veira, D. M. Weary, and M. A. G. von Keyserlingk. 2009. Competition at the feed bunk changes the feeding, standing, and social behavior of transition dairy cows. J. Dairy Sci. 92:3116-3123.

Rabeyrin, M., J. Rushen, and A. M. De Passillé. 2013. Does milk intake or activity soon after birth predict the future growth and health of calves? Page 163 in Proc. 47th Congr. Intl. Soc. Appl Ethol., Florianopolis, Brazil. M. J. Hotzel and L. C. Filho, ed. Wageningen Academic Publishers, Wageningen, the Netherlands.

Rook, A. J., and C. A. Huckle. 1995. Synchronization of ingestive behaviour by grazing dairy cows. Anim. Sci. 60:25-30.

Stanton, A. L., D. F. Kelton, S. J. LeBlanc, J. Wormuth, L. K. Fox, and K. E. Leslie. 2013. Effects of tulathromycin on incidence of various diseases and growth of young heifers. J. Am. Vet. Med. Assoc. 243:267-276

Van Soest, P. J., J. B. Robertson, and B. A. Lew. 1991. Methods for dietary fiber, neutral detergent fiber, and nonstarch polysaccharides in relation to animal nutrition. J. Dairy Sci. 74:3583-3597.

Veissier, I., V. Gesmier, P. Le Neindre, J. Y. Gautier, and G. Bertrand. 1994. The effects of rearing in individual crates on subsequent social behaviour of veal calves. Appl. Anim. Behav. Sci. 41:199-210.

von Keyserlingk, M. A. G., L. Brusius, and D. M. Weary. 2004. Competition for teats and feeding behavior by group-housed dairy calves. J. Dairy Sci. 87:4190-4194.

Warnick, V. D., C. W. Arave, and C. H. Mickelsen. 1977. Effects of group, individual, and isolated rearing of calves on weight gain and behavior. J. Dairy Sci. 60:947-953.

Weber, R., and B. Wechsler. 2001. Reduction in cross-sucking in calves by the use of a modified automatic teat feeder. Appl. Anim. Behav. Sci. 72:215-223. 